\title{
PEMBERDAYAAN POTENSI HUTAN MANGROVE SEBAGAI INDUSTRI EKOWISATA UNTUK MENINGKATKAN PEREKONOMIAN MASYARAKAT PULAU UNTUNG JAWA
}

\author{
Franka Hendra $^{1)}$, Supriyono ${ }^{2)}$, Dwi Suryanto ${ }^{3)}$ dan Cepi Rahmansyah $^{4)}$ \\ ${ }^{1,2,3,4}$ Program Studi Teknik Industri, Fakultas Teknik, Universitas Pamulang
}

\begin{abstract}
Abstrak
Tujuan Pengabdian Masyarakat berjudul "Memberdayakan Potensi Hutan Mangrove sebagai Industri Ekowisata untuk Meningkatkan Ekonomi Masyarakat Pulau Untung Jawa" sebagai upaya untuk memenuhi kewajiban Tri Dharma College. Pengabdian Masyarakat dilakukan di Pulau Untung Jawa, Kepulauan Seribu Provinsi DKI Jakarta pada 9 dan 10 November 2019. Berdasarkan hal di atas, kegiatan pengabdian masyarakat dengan memberikan informasi dan atau pengetahuan tambahan tentang pemberdayaan potensi Hutan Mangrove untuk meningkatkan perekonomian dengan melakukan penyuluhan tentang Hutan Mangrove dan pelatihan singkat tentang teknik untuk memberdayakan Hutan Mangrove dan pemberdayaan masyarakat dalam mengelola industri pariwisata yang dapat diterapkan di Pulau Untung Jawa. Metode yang digunakan dalam Pengabdian Masyarakat adalah dalam bentuk studi pendahuluan tentang Hutan Manrove dan wawancara dengan masyarakat dan para pemangku kepentingan dan kemudian melakukan pertemuan dengan masyarakat untuk memberikan konseling, diskusi dan pelatihan singkat terkait dengan pengelolaan industri pariwisata khususnya ekowisata Hutan Mangrove. Hasil Pengabdian Masyarakat yang diperoleh adalah sejumlah strategi untuk perencanaan teknik pengolahan Hutan Mangrove, strategi pemberdayaan masyarakat dalam mengelola industri pariwisata dan mengidentifikasi potensi lain di Pulua Untung Jawa sebagai faktor pendukung untuk Industri Ekowisata Hutan Mangrove. Kegiatan ini diharapkan dapat memberikan masukan dan informasi terkait potensi pemberdayaan hutan mangrove untuk menjadi industri ekowisata yang dapat meningkatkan perekonomian masyarakat di Pulau Untung Jawa.
\end{abstract}

Kata Kunci: Hutan Mangrove, Industri Ekowisata, Ekonomi

\begin{abstract}
The purpose of Community Service entitled "Empowering the Potential of Mangrove Forests as an Ecotourism Industry to Improve the Economy of the People of Untung Jawa Island" as an effort to fulfill the obligations of Tri Dharma College. Community service was carried out in Untung Jawa Island, Kepulauan Seribu, DKI Jakarta Province on 9 and 10 November 2019. Based on the above, community service activities by providing additional information and / or knowledge about empowering the potential of Mangrove Forests to improve the economy by conducting counseling on Mangrove Forests and short training on techniques to empower Mangrove Forests and community empowerment in managing the tourism industry that can be applied in Untung Jawa Island. The method used in Community Service is in the form of a preliminary study on Mangrove Forest and interviews with the community and stakeholders and then conducting meetings with the community to provide counseling, discussion and brief training related to the management of the tourism industry, especially Mangrove Forest ecotourism. The results of Community Service obtained are a number of strategies for planning mangrove forest processing techniques, community empowerment strategies in managing the tourism industry
\end{abstract}


Pemberdayaan Potensi Hutan Mangrove Sebagai Industri Ekowisata Untuk Meningkatkan Perekonomian Masyarakat Pulau Untung Jawa ... (Franka Hendra) | 109-118

and identifying other potentials in Pulua Untung Jawa as supporting factors for the Mangrove Forest Ecotourism Industry. This activity is expected to provide input and information related to the potential for empowering mangrove forests to become an ecotourism industry that can improve the economy of the people on Untung Jawa Island.

Keywords: mangrove forest, ecotourism industry, economy

Correspondence author: Franka Hendra, dosen01508@unpam.ac.id, Indonesia

\section{PENDAHULUAN}

\subsection{Latar Belakang}

Indonesia adalah negara kepulauan yang mempunyai luas laut $6.315 .222 \mathrm{Km}^{2}$ dengan pantai yang panjangnya sekitar $99.093 \mathrm{Km}$ yang dihialsi oleh keanekaragaman hayati. (Diposaptono, 2015). Hal ini merpukan aset yang tidak ternilai dengan berbagai potensi yang dihasilkan pada jasa transportasi, perikanan, bioteknologi kelautan, bangunan laut, industri kelautan dan lain-lain.. Masyarakat yang hidup pada pesisir pantai menggantungkan perekomomian mereka pada sektor perikanan dan wisata bahari. Dengan meningkatnya pariwisata pantai sejak 2015, tingkat perekomomian diperkirakan dari wisata bahari meningkat mencapai 24 triliun rupiah (Kadin, 2015).

Hutan mangrove meerupakan salah satu potensi wisata bahasi yang dimiliki Indonesia dengan luas hutan mangrove yang paling besar di dunia (Noor, 1999). Hal ini manjadi indikator bahwa potensi hutan mangrove Indonesia sangat besar. Namun hal itu tidak dapat dipergunakan secara optimal dikarenakan oleh banyak faktor, baik faktor alami atau karena tindakan masyarakat sekitar.

Sebagai faktor utama untuk terpeliharanya hutan mangrove tersebut harus mempunyai kesadaraan tentang besarnya potensi hutan mangrove. Pulau Untung Jawa memiliki potensi besar untuk menjadi ekowisata dengan pemberdayaan hutan mangrove. Pulau Untung Jawa mempunyai luas hutan mangrove 3,46 Ha. Saat ini kaawasan hutan mangrove terancam oleh gangguan-gangguan, seperti sampah yang ada di antara akar mangrove yang berasal dari pengunjung dan sampah yang berasal dari tanah.

Dari hasil survei lapangan yang dilakukan sebelum kegiatan bahwa permasalahan yang terjadi adalah kurangnya pengetahuan dan kesadaran masyarakat dalam melakukan pengelolaan hutan mangrove. Peran serta masyarakat merupakan hal yang paling penting dalam meningkatkan kelestarian hutan mangrove sehngga bisa menigkatkan perekonomian masyarakat. Berdasarkan masalah di atas, muncul pertanyaan ilmiah, yaitu bagaimana partisipasi masyarakat dalam pengembangan ekowisata mangrove di pulau Untung Jawa? 


\subsection{Mangrove}

Menurut Nybakken and Perron (1988) mangrove adalah sebutan umum yang digunakan untuk menggambarkan komunitas pesisir tropis yang didominasi oleh sejumlah spesies pohon atau semak yang memiliki kemampuan untuk tumbuh di perairan asin. Hutan mangrove adalah salah satu hutan karbon terkaya di daerah tropis, dan mendukung berbagai jasa ekosistem termasuk perikanan dan siklus batubara (Donato et al., 2012).

Manarove memiliki komponen sumber daya alam dalam bentuk lanskap, flora, fauna dan komunitas lokal yang diintegrasikan ke dalam satu ekosistem yang memiliki fungsi ekologis, ekonomi dan sosial yang sangat penting dalam pengembangan dan pengembangan wilayah pesisir (Wardhani, 2011).

Tetapi tingkat kerusakan hutan mangrove meningkat setiap tahun karena beberapa faktor, salah satunya adalah karena pertumbuhan populasi $1,34 \%$ per tahun dan kepadatan populasi yang terus meningkat sebesar 3,84\% per tahun, yang menyebabkan 50\% mangrove mengalami kerusakan karena pembangunan pemukiman, pelabuhan, dan akuakultur (Kusmana et al., 2008; Mulyadi, Hendriyanto, \& Fitriani, 2010). Karena mangrove perlu mendapat perhatian penting dengan cara pengolahan berbasis masyarakat, yaitu dengan melibatkan diri dalam pengelolaan sumber daya alam di satu wilayah.

\subsection{Manfaat Mangrove}

Pada konferensi global di Bali pada bulan Desember 2007, menempatkan Hutan Mangrove adalah salah satu faktor yang berkontribusi dalam menekan perubahan iklim (Purnobasuki, 2012). Ekosistem hutan mangrove sangat bermanfaat dalam hal ekologi, ekonomi, fisik, kimia, biologi, dan lainnya, yang secara lengkap menurut Santoso and Arifin (1998) adalah:

1). Ekologi

Secara ekologis manfaat mangrove adalah sebagai berikut:

a. Pelindung pantai dari abrasi,

b. Mempercepat perluasan pantai melalui sedimentasi,

c. Mencegah intrusi air laut ke darat, Tempat

d. pemijahan berbagai biota laut,

e. Tempat berteduh dan pengembangbiakan berbagai spesies burung, mamalia, reptil, dan serangga, sebagai pengatur iklim mikro.

\section{2). Fisik}

Secara fisik manfaat mangrove adalah sebagai berikut:

a. Mempertahankanstabil

b. garis pantai yangMelindungi pantai dari erosi,

c. Memegang angin kencang dari laut ke darat,

d. Memegang sedimen,

e. Sebagai zona penyangga rembesan air laut ke darat.

3). Kimia

Secara kimia manfaat mangrove adalah sebagai berikut:

a. Sebagai situs dari proses daur ulang yang menghasilkan oksigen

b. karbon dioksida penyerap,

c. sebagai bahan pengolahan-limbah bahan hasil polusi industri dan kapalkapal di laut, 
Pemberdayaan Potensi Hutan Mangrove Sebagai Industri Ekowisata Untuk Meningkatkan Perekonomian Masyarakat Pulau Untung Jawa ... (Franka Hendra)|111-118

4). Ekonomi

Dalam manfaat ekonomi mangrove adalah sebagai berikut :

a. Kebutuhan rumah tangga produsen (kayu bakar, arang, bahan bangunan, bahan makanan, dan obat-obatan),

b. produsen penggunaan industri (bahan baku kertas, tekstil, kosmetik, penyamak kulit, pewarna),

c. produsen benih ikan, nener udang, kepiting, kepiting, kerang, madu dan telur burung,

d. pariwisata, penelitian dan pendidikan.

5). Pariwisata

Dalam aspek pariwisata, manfaat mangrove adalah sebagai berikut:

a. Sebagai kawasan wisata pantai alami dengan vegetasi dan hewan yang indah,

b. Sebagai tempat untuk pendidikan, konservasi, dan penelitian.

\subsection{Ekowisata Hutan Mangrove}

Indonesia yang terletak di wilayah tropis sangat kaya dengan bermacammacam flora, fauna, serta keanekaragaman biologi yang lain. Kekayaan alam yang melimpah ini bisa dijadikan objek serta energi tarik wisata, paling utama ekowisata. Bagi Sudarto (1999) dalam Sudiarta and Geldart (2006), secara universal sumber energi alam yang bisa digunakan bagaikan objek serta energi tarik ekowisata merupakan hutan hujan tropis, mangrovehutan, hutan sagu, gunung es, serta fauna sangat jarang semacam gajah, naga, orangutan, harimau, badak, cendrawasih, jalak putih, serta yang lain (Sudiarta \& Geldart, 2006).

Ekowisata yang ialah salah satu upaya buat memprioritaskan bermacam produk wisata berbasis sumber energi alam, pengelolaan ekowisata buat meminimalkan akibat terhadap area, pembelajaran berbasis area, donasi terhadap upaya konservasi serta kenaikan kesejahteraan untuk warga lokal( World Tourism Organization, 2002 di Fahriansyah and Yoswaty (2012). Wisata ekologis merupakan wujud pemanfaatan sumber energi alam yang mengandalkan jasa alam buat kepuasan manusia. Ekowisata pesisir serta laut tidak cuma menjual destinasi ataupun objek, namun pula menjual filosofi serta rasa sehingga tidak hendak mengidentifikasi kejenuhan pasar pariwisata (Fahriansyah serta Yoswaty, 2012). Pengembangan ekowisata berkepanjangan bertujuan buat membagikan pengalaman wisata yang bermutu serta tingkatkan mutu hidup warga setempat (Fennell, He, \& Sloan, 2008; Jamal, 2019).

Pada tahun 1992 Pusat Data Mangrove (MIC) didirikan dan merupakan proyek kerja sama antara Pemerintah Indonesia dengan Pemerintah Jepang. Proyek ini bertujuan untuk mengenali serta mengeksplorasi metode reboisasi yang bisa dicoba untuk memulihkan keadaan hutan mangrove yang sudah rusak. Metode yang ditemui merupakan metode menanam serta menanam mangrove. Tingginya bayaran operasional proyek yang dilaksanakan di Pusat Data Mangrove (MIC) sudah menimbulkan kekhawatiran tentang minimnya dana proyek serta pemeliharaan serta pelatihan hutan mangrove di Halaman Hutan Ngurah Rai, paling utama di Pusat Data Mangrove (MIC), lahirlah ide- ide serta terobosan baru yang diharapkan bisa menolong menutupi kekurangan dana. Ilham brilian ini berikutnya 
diimplementasikan oleh pengembangan objek ekowisata di Pusat Data Mangrove (MIC) (Sudiarta, 2006).

\section{METODE PELAKSANAAN} metode:

Metode pelaksanaan kegiatan pengabdian masyarakat dilakukan dengan dua

1). Melakukan Studi Pendahuluan

a. Studi pendahuluan dilakukan dengan memeriksa studi tentang potensi hutan mangrove di Pulau Untung Jawa

b. Studi industri ekowisata hutan mangrove sebelumnya

c. Studi tentang pemberdayaan hutan mangrove sebagai industri ekowisata.

d. Subjek penelitian dengan mengamati kondisi hutan mangrove yang ada di Pulau Untung Jawa

e. Pengamatan Observasi kegiatan masyarakat pada Pulau Untung Jawa

f. Pengamatan Ekowisata Untung Jawa pada Pulau Untung Jawa

2). Rapat Diskusi

a. Memberikan penyuluhan kepada masyarakat dalam forum diskusi disertai dengan sesi tanya jawab dan memberikan pelatihan kepada masyarakat dalam hal pengelolaan industri ekowisata hutan mangrove.

b. Pertemuan tersebut dihadiri oleh pejabat dan warga setempat.

\section{HASIL DAN PEMBAHASAN}

\subsection{Identifikasi Potensi Hutan Mangrove Pulau Untung Jawa}

Hutan mangrove membagikan banyak manfaat untuk warga, terutama yang tinggal di pulau-pulau tersebut, baik secara langsung ataupun tidak langsung. (1) Dengan guna hutan mangrove, yang melindungi area dari dampak oseanografi (pasang surut, arus, angin topan), melindungi pasokan air bersih, mengatur abrasi, menghindari intrusi air laut ke darat, mengatur banjir, melindungi stabilitas tangkapan air tanah, serta mitigasi pergantian hawa tiba- tiba; (2) Guna biologis, bagaikan penyedia keanekaragaman biologi, tempat pembibitan, tempat mencari makan, dan tempat pemijahan untuk beberapa tipe ikan serta udang, dan pemasok nutrisi utama di tepi laut; (3) guna ekonomi, bagaikan sumber kayu kelas satu, bubur kayu, bahan kertas, keripik, serta arang. Pergantian guna hutan mangrove bisa menimbulkan hilangnya guna serta nilai (khasiat) hutan mangrove.

Hutan mangrove di pulau Untung Jawa mempunyai potensi besar menjadi sebuah ekowisata. Ini menjadi salah satu strategi pengembangan Kepulauan Seribu, ialah mengelola sumber energi alam pulau serta meningkatkan industri ekowisata laut Pulau Untung Jawa Dengan mempunyai hutan mangrove seluas 3,46 Ha serta dengan fungsi utama pulau ini yang diresmikan sebagai pulau berpenduduk, perihal ini bisa memunculkan permasalahan sebab persimpangan kegiatan manusia dengan ekosistem mangrove, hingga butuh buat mempunyai penyeimbang buat menanggulangi perihal ini melalui ekowisata. 
Pemberdayaan Potensi Hutan Mangrove Sebagai Industri Ekowisata Untuk Meningkatkan Perekonomian Masyarakat Pulau Untung Jawa ... (Franka Hendra) | 113-118

Pengelolaan pendidikan dan pelatihan berbasis adalah salah satu alternatif yang dapat diandalkan dalam menyediakan berbagai komponen kehidupan di kawasan hutan mangrove untuk hidup, tumbuh, dan berkembang. Dosen dan mahasiswa Universitas Pamulang mengadakan Pendidikan dan Pelatihan Konservasi Mangrove untuk Pengembangan Ekowisata di Desa Pagatan Besar, Kabupaten Tanah Laut.

Kegiatan pengabdian masyarakat berfokus pada para pemuda dan pejabat pemerintah desa setempat. Untuk memberikan peningkatan wawasan dan pengetahuan yang diberikan kepada masyarakat tentang dasar-dasar ekowisata, terutama hutan mangrove, konservasi di kawasan mangrove, pengantar jenis-jenis makhluk hidup yang menghuni kawasan mangrove, undang-undang konservasi, pendidikan lingkungan. Konseling ini difokuskan untuk memberi perhatian dan motivasi terkait pemanfaatan hutan mangrove yang diharapkan berkelanjutan dengan tetap menjaga kelestarian lingkungan. Pengembangan kawasan hutan mangrove membutuhkan perhatian dan kepedulian dari semua pihak, baik masyarakat maupun pemerintah.

Salah satu upaya yang diusulkan dalam kegiatan ini adalah penggunaan sumber daya lokal secara optimal dengan mengembangkan pariwisata berdasarkan konsep industri ekowisata. Wisata mangrove tidak terlepas dari upaya konservasi, pemberdayaan ekonomi dan budaya lokal. Model industri ekowisata di hutan angrove diharapkan dapat menarik wisatawan untuk berkunjung ke objek wisata berbasis alam, budaya populasi lokal, dan potensi lokal.

Dengan bertambahnya pengetahuan masyarakat setempat akan memicu kreativitas dan ide dalam memberdayakan potensi hutan mangrove menjadi wisata bahari nusantara yang dapat melibatkan anak muda khususnya dan masyarakat pulau Untung Jawa secara umum dalam pengelolaan industri ekowisata yang dikoordinasikan dan oleh pemerintah daerah untuk lebih terorganisir dan terstruktur.

\subsection{Strategi Pengolahan Ekowisata Hutan Mangrove}

Pada kegiatan ini akan memberikan bebrapa stategi kepada masayarakat untuk bisa memberdayakan potensi hutan mangrove ini menjadi salah satu ekowisata yang akan meningkatkan perekonomian masyarakat dengan menahajak peran aktif masyarkat dalam menerapkan strategi tersebut. Ada beberapa strategi yang menjadi masukan kepada masyarakat pulau Untung Jawa dalam melakukan pengelolaan hutan mangrove yaitu:

\subsubsection{Rancangan teknis pengelolaan}

Dalam kegiatan ini akan memberikan strategi kepada masyarakat untuk dapat memberdayakan potensi hutan mangrove ini menjadi salah satu ekowisata yang akan meningkatkan perekonomian masyarakat dengan mempromosikan peran aktif masyarakat dalam menerapkan strategi tersebut. Ada beberapa strategi yang menjadi masukan bagi masyarakat pulau Untung Jawa dalam mengelola hutan mangrove, yaitu: 
1). Manajemen Teknis Pengelolaan

RancanganRencana yang diusulkan untuk kegiatan ini adalah:

a. Pengaturan zona: untuk meminimalkan kerusakan dan menjaga fungsi ekologis dan ekonomi kawasan tersebut.

b. Reboisasi: penanaman kembali area mangrove dengan vegetasi yang cocok

Mengembalikan mangrove ke kondisi semula (mis. Area mangrove yang terdiri dari $80 \%$ kolam dan $20 \%$ hutan diubah menjadi $20 \%$ kolam dan $80 \%$ hutan)

Rintangan untuk program reboisasi:

- Kedalaman air lebih dari $1 \mathrm{~m}$ akan membuat sulit untuk menanam benih mangrove. Solusi: bibit mangrove ditanam di bambu yang mengandung lumpur yang tersangkut di substrat.

- Abrasi (tidak adanya lumpur untuk menanam bibit mangrove). Solusi: memasang "groin" dari tumpukan batu atau bambu untuk menahan lumpur agar tidak hanyut ke laut.

c. Pengembangan hutan mina: pemanfaatan hutan mangrove untuk usaha perikanan dengan mempertimbangkan kelestarian kawasan, seperti:

- Parit Empang dengan posisi hutan di tengah dan kolom di sekitar hutan mangrove

- Empang Inti, dengan posisi kolam di tengah dan hutan di sekitar kolam

Agar hutan mangrove dapat dilakukan dengan baik, dapat menerapkan beberapa cara:

- Tahap terakhir penebangan dilakukan 5 tahun setelah dimulainya penebangan.

- Di area penebangan harus ada 64-100 pohon / hektar kiri (jumlah pohon tergantung pada tingkat kesuburan tanah).

- Menebang dalam 2 tahap. Penebangan pertama mencakup 40\% dari total tegakan dan sisanya ditebang dalam 2-5 tahun, tergantung pada keberhasilan atau kegagalan proses degradasi hutan.

- Sistem kanopi 2: penebangan pertama 50\% dari total tegakan dan sisanya ditebang 15-20 tahun kemudian setelah anakan mangrove besar.

d. Pembentukan kelembagaan: perlu untuk membentuk lembaga yang jelas untuk menangani kawasan mangrove secara keseluruhan.

2). Pemberdayaan Masyarakat

Untuk mewujudkan keberhasilan pengelolaan ekowisata, perlu memberdayakan masyarakat. Sehingga masyarakat dapat merasakan manfaat ekowisata itu sendiri. Memberdayakan masyarakat dianggap lebih penting daripada melibatkan masyarakat.

Sebagai khalifah di bumi, manusia memiliki kewajiban untuk melestarikan alam semesta dan lingkungan sebaik mungkin. Agar bisa hidup di dunia yang makmur penuh berkah dan menjadi bekal di akhirat. Manusia sebagai Khalifah Allah di muka bumi harus bertindak bijak dan 
Pemberdayaan Potensi Hutan Mangrove Sebagai Industri Ekowisata Untuk Meningkatkan Perekonomian Masyarakat Pulau Untung Jawa ... (Franka Hendra) | 115-118

bijak dalam mengelola kekayaan alam dan lingkungan, sehingga bumi terlindung dari kerusakan dan tetap abadi.

Dalam kegiatan ini dilakukan briefing tentang bagaimana memberdayakan masyarakat Pulau Untung Jawa untuk mengambil bagian dalam mengembangkan pariwisata di Pulau Untung Jawa, terutama pengelolaan ekowisata Hutan Mangrove. Aspek pemberdayaan masyarakat yang disajikan adalah sebagai berikut:

a. Potensi pengembangan, kapasitas dan partisipasi masyarakat melalui pengembangan sektor bisnis pariwisata dengan strategi:

- Memetakan potensi dan kebutuhan penguatan kapasitas masyarakat lokal dalam pengembangan pariwisata

- Memberdayakan potensi dan kapasitas masyarakat lokal dalam pengembangan pariwisata

- Memperkuat lembaga masyarakat dan pemerintah di tingkat lokal untuk mendorong kapasitas dan peran masyarakat dalam mengembangkan pariwisata.

b. Meningkatkan potensi dan kapasitas sumber daya lokal melalui pengembangan sektor bisnis pariwisata dengan strategi untuk

- meningkatkan potensi dan kapasitas sumber daya lokal melalui pengembangan sektor bisnis pariwisata;

- Mengembangkan potensi sumber daya lokal melalui desa-desa pariwisata dan desa-desa kreatif.

- Meningkatkan kualitas produk UMKM sebagai komponen pendukung pariwisata di destinasi wisata.

- Meningkatkan kemampuan pengusaha UMKM untuk mengembangkan masyarakat.

c. Perlindungan dan pemberian insentif untuk mendorong UMKM dalam penawaran untuk bisnis pariwisata yang dikembangkan secara lokal sesuai dengan hukum dan peraturan dengan:

- Mendorong pemberian insentif dan fasilitas untuk pengembangan UMKM dalam bisnis pariwisata sesuai dengan ketentuan perundang-undangan.

- Perlindungan keberlanjutan UMKM di sektor bisnis pariwisata.

- Memperkuat bisnis kemitraan rantai nilai di bidang pariwisata dan perdagangan melalui kerja sama antara bisnis pariwisata dan industri skala UMKM di sekitar tujuan wisata dalam memberikan layanan kepada wisatawan; dan Meningkatkan kualitas produk dan layanan UMKM dalam bisnis pariwisata dan ecraf bidqang dalam memenuhi standar pasar.

d. Perluasan akses pasar untuk produk bisnis tawaran UMKM yang dikembangkan oleh masyarakat di sekitar tujuan wisata dengan memperkuat akses dan jaringan bisnis pariwisata mikro, kecil dan menengah dengan sumber potensial dari informasi pasar dan global dan meningkatkan tanggung jawab sosial dan lingkungan bisnis besar dalam upaya untuk memperluas akses pasar untuk produk bisnis pariwisata UMKM. 
e. Peningkatan akses dan dukungan modal dalam upaya mengembangkan produk bisnis tawaran UKM yang dikembangkan oleh masyarakat di sekitar lokasi wisata. Dengan strategi:

- Mendorong pemberian insentif dan kemudahan akses ke modal untuk UMKM dalam bisnis pariwisata sesuai dengan perundangundangan

- Mendorong pemberian bantuan modal untuk mendukung pengembangan UMKM dalam bisnis pariwisata.

f. Meningkatkan kesadaran dan peran masyarakat dan pemangku kepentingan terkait dalam mewujudkan Sapta Pesona untuk menciptakan iklim yang kondusif bagi pariwisata lokal.

g. Meningkatkan motivasi dan kemampuan untuk mengenali dan mencintai bangsa dan negara melalui perjalanan wisata kepulauan dengan mengembangkan pariwisata sebagai investasi dalam pengetahuan dan meningkatkan kualitas dan kuantitas informasi pariwisata kepulauan kepada publik.

\subsection{Identifikasi Potensi Lainnya Sebagai Faktro Pendukung}

Sebagai daerah yang berkembang menjadi tujuan wisata Pulau Untung Jawa sudah memiliki potensi lain sebagai faktor pendukung yang dapat diintegrasikan dalam strategi pemberdayaan hutan mangrove. Berdasarkan wawancara dan diskusi yang dilakukan dengan komunitas pulau Untung Jawa, ada beberapa potensi lain yaitu:

1) Cindramata

Sebagai kenang-kenangan dari pulau Untung Jawa, masyarakat menyediakan cinderamata dalam bentuk kerajinan tangan dari industri rumah tangga.

2) Jajanan khas pantai

Komunitas Pulau Untung Jawa memiliki saung kecil (saung) yang menyediakan berbagai jajanan khas pantai untuk wisatawan yang datang ke Pulau Unntung Jawa seperti; ikan bakar atau pilih ikan hidup sendiri untuk diproses.

3) Home Stay

Bagi wisatawan yang menghabiskan waktu liburan di Pulau Untung Jawa dalam beberapa hari tidak perlu khawatir dengan penginapan, karena di Pulau Untung, Jawa menyediakan banyak home stay yang memiliki fasilitas yang tidak kalah dengan penginapan pada umumnya, yang memberikan kenyamanan bagi wisatawan yang menginap.

4) Penyewaan sepeda dan Speed Boat

Bagi wisatawan yang suka mengendarai sepeda, pulau Untung Jawa juga menyediakan penyewaan sepeda untuk berkeliling pulau dan speed boat untuk berkeliling ke pulau-pulau lain sambil melihat keindahan hutan mangrove. 
Pemberdayaan Potensi Hutan Mangrove Sebagai Industri Ekowisata Untuk Meningkatkan Perekonomian Masyarakat Pulau Untung Jawa ... (Franka Hendra) | 117-118

\section{SIMPULAN}

Berdasarkan hasil pelaksanaan kegiatan ini dapat disimpulkan sebagai berikut:

1). Pulau Untung Jawa memiliki banyak potensi wisata yang dapat dikembangkan, salah satunya adalah ekowisata Hutan Mangrove. Tidak hanya melestarikan ekosistem tetapi juga memberikan pemandangan yang indah juga dapat meningkatkan ekonomi masyarakat dengan mengundang atraksi wisata pertambangan untuk meningkatkan jumlah pengunjung yang datang ke Pulau Untung Jawa.

2). Ada beberapa strategi yang dapat diterapkan untuk meningkatkan potensi ekowisata Hutan Mangrove Pulau Untung Jawa, yaitu:

a. Merencanakan desain teknik pengelolaan Hutan Mangrove dengan zonasi untuk meminimalkan kerusakan dan melestarikan ekosistem dan ekonomi daerah, penghijauan kawasan penanaman kembali hutan mangrove dengan tanaman yang cocok.

b. Memberdayakan masyarakat dalam mengelola ekowisata Hutan Manngrove sehingga masyarakat dapat memperoleh manfaat dari keberadaan ekowisata itu sendiri.

c. Identifikasi dan integrasikan potensi lain di Pulau Untung Jawa untuk mendukung ekowisata Hutan Mangrove seperti suvenir, jajanan khas pantai, penginapan dan fasilitas lain yang memberikan layanan kepada wisatawan.

Adapun saran - saran dari hasil pengabdian kepada masyarakat ini yaitu peran pemerintah daerah diperlukan untuk pengelolaan wilayah pesisir dalam pemberdayaan masyarakat dan pengelolaan wilayah pesisir dan pulau-pulau kecil dengan perlindungan hukum berdasarkan undang-undang. Untuk alasan ini, keberhasilan dan keberlanjutan program ini kami sarankan peran aktif semua lapisan masyarakat Untung Jawa dalam pengembangan potensi Hutan Mangrove sebagai Industri Ekowisata, dan program ini harus mendapat dukungan dari pemerintah daerah DKI Jakarta untuk memfasilitasi secara material dan material untuk mengembangkan tempat-tempat wisata di DKI Jakarta, khususnya di Pulau Untung Jawa.

Dengan terlaksananya kegiatan Pengabdian Kepada Masyarakat ini dengan lancar dan terkendali kami mengucapkan terima kasih pada pihak-pihak yang telah mendukung terlaksananya kegiatan ini antara lain Lembaga Penelitian dan Pengabdian Kepada Masyarakat Universitas Pamulang, Pemerintah Daerah Kepulauan Seribu DKI Jakarta, Lurah Pulau Untung Jawa dan Masyarakat kelurahan Pulau Untung Jawa

\section{DAFTAR PUSTAKA (14pt, bold)}

Donato, D. C., Kauffman, J. B., Murdiyarso, D., Kurnianto, S., Stidham, M., \& Kanninen, M. (2012). Mangrove adalah salah satu hutan terkaya karbon di kawasan tropis. Brief CIFOR, 12, 1-10.

Fahriansyah, \& Yoswaty, D. (2012). Pembangunan ekowisata di kecamatan tanjung balai asahan, sumatera utara: faktor ekologis hutan mangrove. Jurnal Ilmu dan Teknologi Kelautan Tropis, 4(2), 346-359.

Fennell, M. J., He, L., \& Sloan, M. K. (2008). Analyte monitoring system and methods: Google Patents. 
Jamal, F. (2019). PERAN PEMERINTAH DAERAH DALAM PENGELOLAAN WILAYAH PESISIR. RECHTSREGEL Jurnal Ilmu Hukum, 2(1).

Kusmana, C., Istomo, W. C., Budi, S., Siregar, I., Tiryana, T., \& Sukardjo, S. (2008). Manual Silvikultur Mangrove di Indonesia. Departemen Kehutanan Republik Indonesia dan Korea International Cooperation Agency (KOICA). Jakarta (ID): Korea International Cooperation Agency (KOICA) The Rehabilition Mangrove Forest ana Coastal Area damaged By Tsunami in Aceh Project.

Mulyadi, E., Hendriyanto, O., \& Fitriani, N. (2010). Konservasi hutan mangrove sebagai ekowisata. Jurnal Ilmiah Teknik Lingkungan, 2(1), 11-18.

Nybakken, J., \& Perron, F. (1988). Ontogenetic change in the radula of Conus magus (Gastropoda). Marine Biology, 98(2), 239-242.

Purnobasuki, H. (2012). Pemanfaatan hutan mangrove sebagai penyimpan karbon. Buletin PSL Universitas Surabaya, 28(3-5), 1-6.

Santoso, N., \& Arifin, H. (1998). Rehabilitas Hutan Mangrove Pada Jalur Hijau Di Indonesia. Lembaga Pengkajian dan Pengembangan Mangrove (LPP Mangrove). Jakarta, Indonesia.

Sudarto, G. (1999). Ekowisata: wahana pelestarian alam, pengembangan ekonomi berkelanjutan, dan pemberdayaan masyarakat: Yayasan Kalpataru Bahari bekerjasama dengan Kehati.

Sudiarta, I. W., \& Geldart, D. W. (2006). Interaction energy of a water molecule with a single-layer graphitic surface modeled by hydrogen-and fluorine-terminated clusters. The Journal of Physical Chemistry A, 110(35), 10501-10506.

Wardhani, M. K. (2011). Kawasan konservasi mangrove: suatu potensi ekowisata. Jurnal Kelautan: Indonesian Journal of Marine Science and Technology, 4(1), 60-76. 